Jurnal Pemberdayaan: Publikasi Hasil Pengabdian kepada Masyarakat

Vol. 3, No. 2, Agustus 2019, Hal. 191-198

ISSN: 2580-2569; e-ISSN: 2656-0542

DOI: https://doi.org/10.12928/jp.v3i2.1081

\title{
Pembekalan keterampilan ojek Difa city tour untuk mewujudkan kesetaraan kaum disabilitas
}

\author{
Dianna Ratnawati, Desy Rufaidah, Nurcholish Arifin Handoyono \\ Universitas Sarjanawiyata Tamansiswa, Fakultas Keguruan dan Ilmu Pendidikan, Pendidikan Teknik \\ Mesin Jl.Batikan UH III/1043, Umbulharjo, Yogyakarta \\ Email: dianna.ratnawati@ustjogja.ac.id
}

\begin{abstract}
ABSTRAK
Difa City Tour merupakan usaha jasa ojek online satu-satunya di Indonesia dengan driver dan mayoritas member kaum disabilitas di Yogyakarta. Namun di lingkungan masyarakat masih terjadi diskriminasi disamping kemandirian yang diunjukkan ojek ini. Pengabdian kepada masyarakat ini bertujuan untuk : (1) memberi penyuluhan prinsip ergonomi dalam berkendara; (2) melatih keterampilan desain autocad; (3) melatih keterampilan pengelasan; (4) melatih keterampilan pengecatan; dan (5) melatih keterampilan public speaking. Metode yang digunakan adalah pelatihan dan pendampingan. Tim pelaksana program terdiri dari tiga dosen dan dua mahasiswa. Pelaksanaan kegiatan diselenggarakan di unit produksi bengkel pendidikan teknik mesin Universitas Sarjana Wiyata Taman Siswa. Hasil dari pelaksanaan pengabdian kepada masyarakat adalah peningkatkan ilmu bidang ergonomic dari peserta $90 \%, 75 \%$ peserta terampil mengoperasikan aplikasi autocad, $85 \%$ terampil las dasar, $85 \%$ terampil mengecat, dan $90 \%$ terampil berkomunikasi. Program yang telah dilaksanakan tersebut memberikan dampak positif bagi peserta yang dapat dilihat dari peningkatan pengetahuan, keterampilan dan pelayanan terhadap member sehingga berpengaruh terhadap produktivitas dan peningkatan kepercayaan pelanggan ojek Difa city tour.
\end{abstract}

Kata kunci : disabilitas, ergonomi, pengelasan, pengecatan, speaking

\begin{abstract}
Difa City Tour is the only online motorcycle taxi service business in Indonesia with drivers and majority members of people with disabilities in Yogyakarta. However, in the community environment, there is still discrimination despite the independence shown by this motorcycle taxi. Community service aims to: (1) provide information on ergonomic principles in driving; (2) practice autocad design skills; (3) train welding skills; (4) practice painting skills; and (5) practice public speaking skills. The method used is training and assistance. The program implementation team consists of three lecturers and two students. The activities carried out in the production unit of the mechanical engineering education workshop at Universitas Sarjanawiyata Tamansiswa. The results of community service were able to improve ergonomics $90 \%$, $75 \%$ of participants were skilled in operating autocad applications, $85 \%$ were basic welding skills, $85 \%$ were painting skills, and $90 \%$ were communication skills. The program that implemented has a positive impact on participants which can be seen from the increase in knowledge, skills, and services for members so that it affects productivity and increases the confidence of customers in the city tour.
\end{abstract}

Keywords : disability, ergonomics, welding, painting, speaking 


\section{PENDAHULUAN}

Jumlah penduduk berkebutuhan khusus/difabel di Daerah Istimewa Yogyakarta hingga tahun 2015 menurut data statistik mencapai 25.050 jiwa atau $0,70 \%$ dari total penduduk provinsi DIY (B. P. Statistik, 2016). Jaminan perlindungan dan pemenuhan hak-hak penyandang disabilitas telah tertulis dalam Perda Povinsi DIY No.4 tahun 2012. Regulasi ini linier dengan UUD 1945 bahwa tiap warga Negara memiliki hak, kewajiban dan kedudukan yang sama. Kemudian dikuatkan dengan UUD RI No.8 tahun 2016 tentang penyandang disabilitas. Meski telah mendapat jaminan hukum terkait kesetaraan kaum difabel, yang masih menjadi permasalahan adalah minimnya kesempatan kerja, diskriminasi kaum minoritas difabel di lingkungan masyarakat masih tinggi, aksesibilitas terhadap angkutan umum dan fasilitas publik untuk kelompok difabel pun masih kesulitan. Di DIY telah muncul usaha jasa yang memfasilitasi kaum disabilitas untuk berdikari secara mandiri dalam mencari nafkah yaitu melalui layanan Difa City Tour.

Difa City Tour merupakan suatu bentuk usaha jasa layanan ojek online yang dirintis di Yogyakarta untuk menyediakan sarana transportasi yang nyaman bagi para difabel. Keunikannya adalah para drivernya orang-orang yang punya kebutuhan khusus dan satusatunya (ojek) di dunia yang betul-betul mengakomodasi para difabel. Usaha ini dirintis oleh Bapak Triyono (35 tahun) di tahun 2015 diluncurkan bertepatan dengan hari difabel Internasional pada 1 Desember 2015. Selama perkembangan 3 tahun ini Difa City Tour telah berhasil merekrut driver usia 21 - 47 tahun sejumlah 22 driver dan akan terus ditambah. Gambar 1 memperlihatkan suasana wawancara dengan owner Difa City Tour.

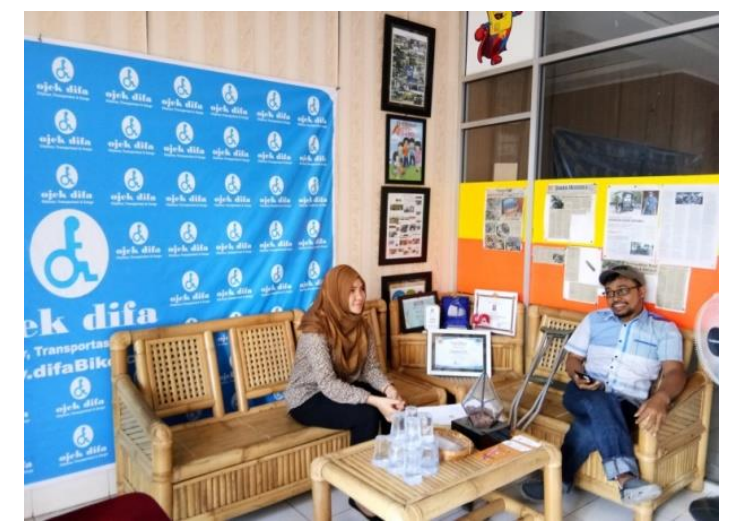

Gambar 1. Wawancara dengan owner Difa City Tour

Berdasarkan hasil wawancara dengan Bapak Triyono selaku owner Difa City Tour pada Kamis, 2 Agustus 2018 kendala yang dihadapi dalam pengembangan jasa ojek online Difa ini diantaranya (1) keterbatasan desain kendaraan ojek Difa yang konstruksinya kurang center dengan tumpuan beban sisi kanan; (2) para driver belum menerapkan prinsip ergonomi dalam berkendara sehingga mudah lelah; (3) pelanggan ojek Difa adalah difabel dengan kategori fisik dan indra. Sehingga saat menemui pelanggan paraplegi, driver membutuhkan kecepatan ekstra pelan dalam mengendarai sepeda motornya, sementara toleransi masyarakat kurang/tidak sabaran terhadap kaum minoritas difabel ini sehingga perlu desain yang mempermudah mobilitas ojek Difa di jalan raya; (4) pelanggan masih suka pilih-pilih driver karena karakteristik pasif/kurang komunikatif yang masih dominan. Gambaran kondisi kendaraan Difa City Tour terlihat pada Gambar 2. 

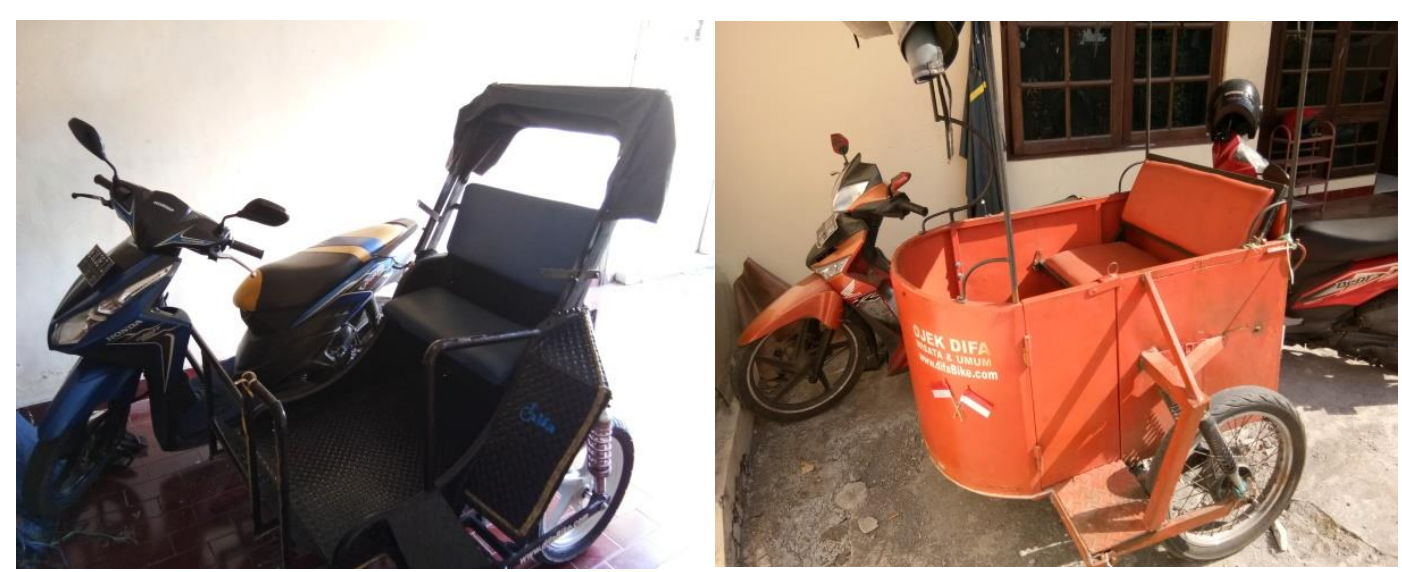

Gambar 2. Kondisi kendaraan Difa City Tour

Jika permasalahan di atas tidak segera diatasi akan berdampak pada produktivitas kerja yang nantinya dapat berdampak pada income dan tingkat kesejahteraan serta menurunkan pandangan sosial masyarakat terhadap disabilitas. Agar dalam meredesain sepeda motor yang lebih ergonomis, maka tim kreatif dan driver perlu dibekali keterampilan melalui kegiatan pengabdian ini. Program yang akan dilaksanakan diantaranya (1) pelatihan ergonomi; (2) pelatihan autocad; (3) pelatihan pengelasan; (4) pelatihan pengecatan; (5) pelatihan public speaking. Adapun tujuan dalam kegiatan pengabdian ini adalah untuk menambah pengetahuan dan keterampilan peserta dalam mendesain sepeda motor yang ergonomis serta meningkatkan kualitas pelayanan terhadap member.

Ergonomi adalah ilmu yang penerapannya berusaha untuk menyerasikan pekerjaan dan lingkungan terhadap orang atau sebaliknya dengan tujuan tercapainya produktivitas dan efisiensi yang setinggi-tingginya melalui pemanfaatan faktor manusia seoptimal-optimalnya (Suma'mur, 1989). Implementasi ergonomi dalam desain alat, mesin, sistem, tugas, pekerjaan dan lingkungan untuk meningkatkan produktivitas, keselamatan, kenyamanan, dan efektifitas peran dari inidividu (Manuaba, 1992). Langkah-langkah implementasi ergonomi dalam desain dimulai dari persiapan kerja proyek, analisis pekerjaan dan kesehatan, perencanaan, pengukuran, penerapan hasil pengukuran dalam perancangan desain, uji coba dan evaluasi (Karwowski and Marras, 2003). Seperti halnya untuk desain tempat duduk untuk sudut yang nyaman kisaran 80-85, namun tetap disesuaikan dengan dimensi antropometri pengguna (Patil dkk, 2014). Data pengukuran yang dibutuhkan untuk menghasilkan sepeda motor yang ergonomis meliputi antropometri struktural dan fungsional (Amrutkar and Rajhans, 2011). Konsep ergonomi tersebut tentu dapat dijadikan bahan pertimbangan dalam mendesain ulang sepeda motor yang ergonomis sehingga dapat meningkatkan jumlah trip perharinya karena dengan desain baru driver tidak mudah capek, nyaman, tidak kepanasan dan kehujanan serta mendapat jaminan keselamatan dan kesehatan kerja demikian halnya dengan pelanggan disamping merasakan kenyamanan juga mendapat jaminan keselamatan dan kesehatan kerja yang berdampak pada promosi, kualitas layanan sehingga jumlah member meningkat.

\section{METODE}

Kegiatan pengabdian kepada masyarakat ini menggunakan metode pelatihan dan pendampingan. Mitra sasaran adalah Difa City Tour Yogyakarta. Subjek sasarannya berjumlah 6 orang dari tim kreatif Difa City Tour. Program kegiatan meliputi pelatihan dan pendampingan ergonomi, autocad, pengelasan, pengecatan dan public speaking. Kegiatan ini diselenggarakan pada bulan Juni sampai September 2019. Kegiatan pelatihan dan pendampingan dalam program kemitraan ini dilaksanakan oleh 3 dosen Prodi Pendidikan Teknik Mesin dan Pendidikan Bahasa dan Sastra Indonesia. Dimana masing-masing dosen memiliki keahlian di bidang keselamatan dan kesehatan kerja, bidang pengelasan dan teknik sepeda motor, 
pengecatan serta keterampilan public speaking. Disamping dosen, kegiatan ini juga melibatkan 2 mahasiswa keahlian otomotif dan mesin untuk membantu desain, produksi, pengelasan hingga pengecatan. Kegiatan pelatihan diselenggarakan di Bengkel Unit Produksi Prodi Pendidikan Teknik Mesin Universitas Sarjanawiyata Tamansiswa yang beralamatkan di Jl. Soga No. 14A Celeban UH II.

\section{HASIL, PEMBAHASAN, DAN DAMPAK}

Hasil dari setiap tahapan kegiatan pengabdian yang telah dilaksanakan meliputi:

a. Pelatihan ergonomi

Pelatihan ini bertujuan membekali pengetahuan kaidah ilmu ergonomi, material/bahan untuk meredesain kendaraan yang lebih ergonomis, prinsip-prinsip ergonomi yang langsung dapat diterapkan saat mengendarai kendaraan. Kegiatan tersebut dapat dilihat pada Gambar 3 yang diselenggarakan pada tanggal 17-18 Juni 2019.

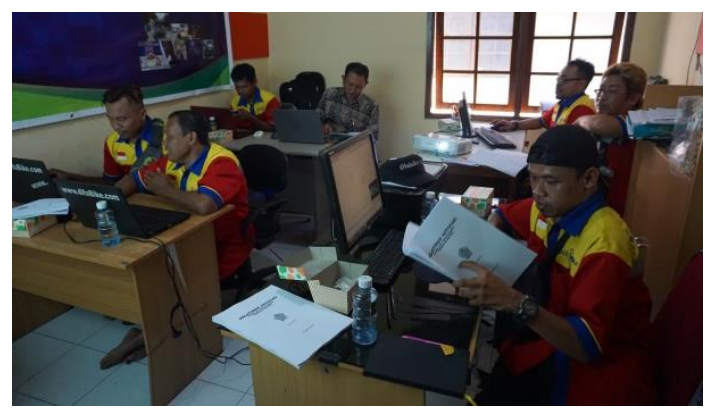

Gambar 3. Pelatihan ergonomi

Peserta yang hadir berjumlah 6 orang. Dalam sesi diskusi peserta aktif bertanya menyampaikan keluhan saat berkendara dan aktif menanyakan solusi terkait ilmu ergonomi yang dapat dipraktikkan diantaranya posisi duduk yang benar, pemilihan bahan yang sesuai untuk desain baru kendaraan yang lebih ergonomis dan teknik berkendara serta perawatan kendaraan. Keseluruhan peserta terlihat antusias mendapatkan ilmu baru dan dapat mempraktikkan dalam bekerja sehari-hari. Tidak ditemui kendala saat kegiatan pelatihan berlangsung.

b. Pelatihan autocad

Pelatihan autocad seperti yang tertera pada Gambar 4 diselenggarakan bersamaan dengan pelatihan ergonomi selama dua hari. Dari kegiatan pelatihan ini peserta dibekali ilmu pengoperasian software autocad dalam mendesain konstruksi rangka dasar sepeda motor yang akan dimodifikasi. Hasil dari pelatihan ini peserta terampil menggunakan software autocad untuk membuat desain 3D membuat desain sambungan rangka dasar. Kendala yang dihadapi yaitu kegiatan pelatihan perlu dilanjutkan dan membutuhkan pendampingan secara berkala hingga peserta secara keseluruhan mahir dan mampu mengembangkan kreatifitasnya dalam membuat desain sepeda motor yang ergonomis. Namun secara keseluruhan peserta dapat mengoperasikan software autocad untuk membuat desain dasar rangka bawah kendaraan. 


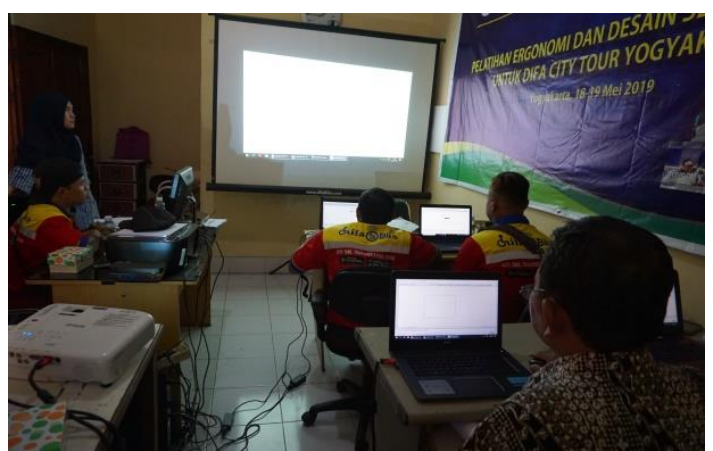

Gambar 4. Pelatihan autocad

c. Pelatihan pengelasan

Pelatihan pengelasan ini diselenggarakan selama tiga hari yaitu tanggal 1-3 Juli 2019 di Bengkel Unit Produksi Pendidikan Teknik Mesin Universitas Sarjanawiyata Tamansiswa. Pelatihan pengelasan dasar dapat dilihat pada Gambar 5.

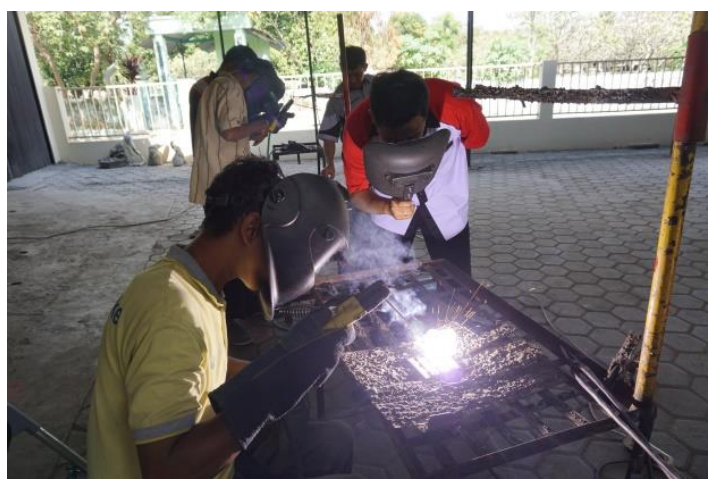

Gambar 5. Pelatihan pengelasan

Berdasarakan pelatihan yang telah diselenggarakan terlihat peserta terampil dalam menyambung dua plat menggunakan las listrik, terlihat dari hasil sambungan rapi dan kuat. Namun untuk dapat mengelas rangka sepeda motor yang sebenarnya membutuhkan pelatihan lebih lanjut karena bahan yang digunakan lebih tebal dan berat. Sebagai ilmu dasar kegiatan pelatihan yang diberikan sudah terselenggara dengan baik.

d. Pelatihan pengecatan

Pelatihan pengecatan dilaksanakan selama dua hari yaitu tanggal 7-8 September 2019 berturut-turut dengan tahapan kegiatan pelatihan cat primer, dempul hingga tahap pengecatan akhir. Gambaran pelatihan ini dapat dilihat pada Gambar 6. Hasil dari kegiatan pelatihan ini adalah peserta terampil dalam mengecat rangka sepeda motor menggunakan spray gun sesuai SOP. Kegiatan ini membutuhkan waktu lama untuk pengeringan cat dasar dan dempul sehingga dilanjutkan pada hari berikutnya untuk finishing. 


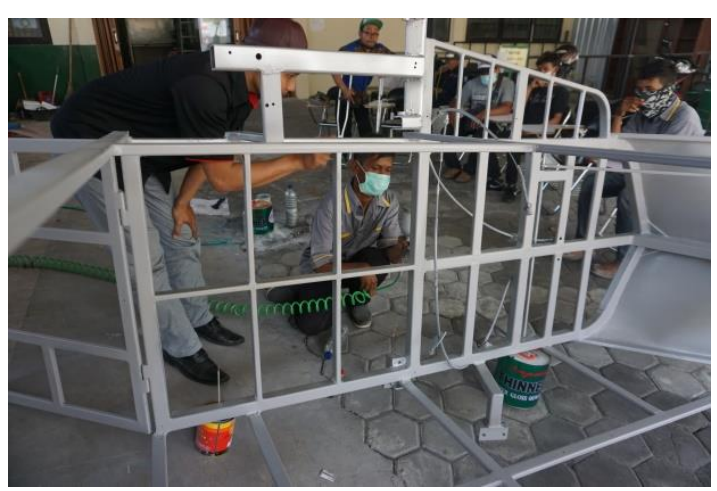

Gambar 6. Pelatihan pengecatan

e. Pelatihan public speaking

Pelatihan public speaking diselenggarakan bersamaan dengan pelatihan pengecatan selama sehari yaitu tanggal 7 September 2019 dengan tujuan untuk meningkatkan ketrampilan komunikasi para driver. Dalam pelatihannya peserta dilatih berkomunikasi lebih interaktif, ramah, sopan dan membuat pelanggan senang. Kegiatan pelatihan ini dapat dilihat pada Gambar 7. Peserta antusias dan praktik komunikasi langsung ada yang berperan sebagai driver dan pelanggan. Hasil pelatihan menunjukkan adanya peningkatan keterampilan komunikasi driver khususnya bagi anggota baru yang semula pendiam menjadi lebih komunikatif, memiliki bahan pembicaraan dengan pelanggan.

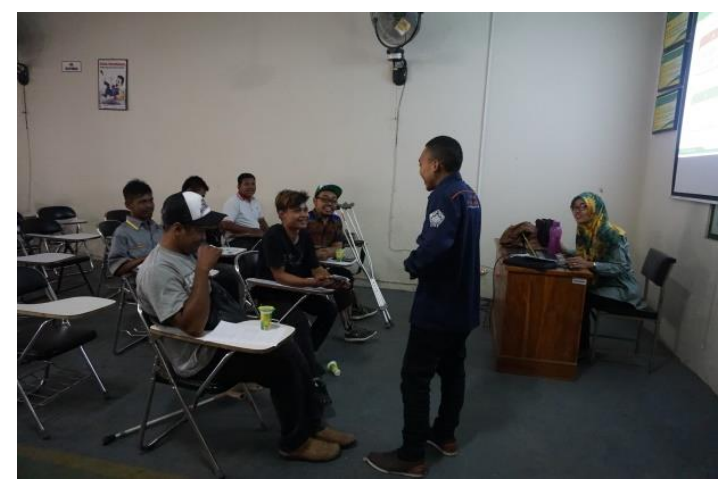

Gambar 7. Pelatihan public speaking

Keberhasilan pengabdian kepada masyarakat ini dapat dilihat dari indikator peningkatan wawasan dan ketrampilan peserta yang ditunjukkan pada Tabel 1 .

Tabel 1. Indikator keberhasilan program pengabdian kepada masyarakat

\begin{tabular}{clcl}
\hline No & \multicolumn{1}{c}{ Jenis Pelatihan } & Jumlah Peserta & \multicolumn{1}{c}{ Hasil } \\
\hline 1. & Pelatihan ergonomi & 6 & $\begin{array}{l}90 \% \text { pengetahuan ergonomi } \\
\text { meningkat }\end{array}$ \\
2. & Pelatihan autocad & 6 & $\begin{array}{l}75 \% \text { terampil mengoperasikan } \\
\text { software autocad }\end{array}$ \\
3. & Pelatihan pengelasan & 6 & $\begin{array}{l}85 \% \text { terampil las dasar } \\
85 \% \text { terampil mengecat } \\
\text { 4. }\end{array}$ \\
5. Pelatihan pengecatan & Pelatihan public speaking & 6 & $90 \%$ terampil berkomunikasi
\end{tabular}


Dampak dari kegiatan pengabdian ini dapat dilihat dari indikator keberhasilan pada Tabel 1. Dampak positif ini diharapkan mendapat tanggapan positif dari pemerintah DIY untuk lebih memberdayakan kaum disabilitas khususnya dalam peningkatan keterampilannya.

\section{SIMPULAN}

Serangkaikan tahapan kegiatan program pengabdian kepada masyarakat untuk Ojek Difa City Tour Yogyakarta dapat diselenggarakan dengan baik. Melalui pelatihan yang diberikan mampu meningkatkan wawasan ergonomi, meningkatkan ketrampilan desain dengan autocad, ketrampilan pengelasan, ketrampilan pengecatan dan meningkatkan ketrampilan komunikasi lisan yang nantinya dapat membantu meningkatkan produktivitas kerja para driver.

\section{UCAPAN TERIMAKASIH}

Keberhasilan program pengabdian kepada masyarakat ini karena bantuan dan dukungan dari berbagai pihak. Kami tim pengabdian mengucapkan banyak terimakasih kepada DRPM (Direktorat Riset dan Pengabdian Masyarakat), Difa City Tour Yogyakarta, LP3M UST dan Prodi Pendidikan Teknik Mesin Universitas Sarjanawiyata Tamansiswa.

\section{DAFTAR PUSTAKA}

A. S. Amrutkar and N. Rajhans, (2011), Ergonomic Posture for Motorcycle Riding, Conference Paper. Researchgate.

B. P. Statistik, (2016), Statistik Daerah Istimewa Yogyakarta 2016, Yogyakarta.

Karwowski, W and W. Marras, (2003), Occupational Ergonomics: Design and Management of Work System. New York: CRC Press.

Manuaba, A., (1992), Bunga Rampai Ergonomi, vol. 1. Udayana, Denpasar.

Patil, M. M., dkk, (2014), Design and Development of Motorcycle Seat from Ergonimics Point of View with Vibration and Discomfort Analysis," Int. J. Mech. Eng. Technol., vol. 5, no. 12, pp. 09-15, 2014.

Suma'mur, (1989), Keselamatan Kerja dan Pencegahan Kecelakaan. Jakarta: CV. Haji Masagung., 
